\title{
OS IMPACTOS DA INDÚSTRIA CULTURAL E CONSUMO NA INFÂNCIA: REFLEXÕES SOBRE O BRINCAR TECNOLÓGICO
}

\author{
Taila Angélica Aparecida da Silva (Pedagogia - UEL) \\ Profa. Dra. Marta Regina Furlan de Oliveira (orientador)
}

\section{RESUMO}

Este texto objetiva discutir os impactos da Indústria Cultural e Consumo na infância, principalmente no que se refere ao brincar industrializado, seja com super-heróis, seja com a Barbie. O estudo é fruto das reflexões relacionadas ao Projeto de Pesquisa "Indústria Cultural, Educação e Trabalho Docente na Primeira Infância: da semiformação à emancipação humana" da Universidade Estadual de Londrina atrelado ao processo de pesquisa relacionado ao Trabalho de Conclusão do Curso de Pedagogia na UEL. Acreditamos que a busca pelo "ter" em detrimento do "ser" torna-se objetivo de muitos que se iludem aos encantos e delírios do consumo e da mercadoria. Diante disso, a partir dos fundamentos da teoria crítica em Adorno e Horkheimer (1985) podemos perceber que mesmo que o consumo seja impactante na vida das pessoas, estas precisam exercer o pensamento crítico e elaborado em favor de novas perspectivas de vida que se distanciem desse conceito equivocado sobre a vida social via utilidade. Essa pesquisa, embora em andamento, precisa ser cada vez mais compreendida, a fim de que possamos desenvolver novos olhares para a sociedade do consumo, que venham a ser superados os valores mercadológicos e consumistas.

Palavras-chave: Indústria Cultural. Consumo. Infância.

\section{INTRODUÇÃO}

Vivemos na era da globalização, onde a sociedade gira em torno do capital, a humanidade se faz escrava do capitalismo e se aliena aos impactos da globalização. Diariamente somos manipulados e induzidos a reproduzir os padrões impostos por uma sociedade capitalista, onde o consumismo exagerado e sem limites, limitam nossa forma de pensar, agir e até mesmo a forma de enxergar o mundo a nossa volta.

Através das contribuições de Adorno e Horkheimer (1985) que trazem uma reflexão pautada nos fundamentos da Teoria Crítica e, que desmistifica o próprio conceito de cultura de massa, uma vez que acreditam que o que acontece não é algo natural, por vontade própria do indivíduo, mas, pela força do contexto mercadológico que impactado pela Indústria Cultural, provoca no indivíduo a conformação com o consumo e com a lógica do mercado e da produção. A indústria cultural integra e administra os níveis de comportamento de um individuo sendo uma ferramenta do sistema capitalista, na qual dissemina cultura e o consumo de massas. A cultura dissemina padrões, havendo a padronização de conceitos ideias seguindo a lógica capitalista.

Diante disso, mediados pelos impactos da Indústria Cultural, o indivíduo passa a ter o desejo de consumir cada vez mais, envolvendo todas as atividades de sua vida: alimentação, vestuário, lazer, moradia, automóveis, brinquedos, etc. Estas mercadorias 


\section{SEMINÁRIO DE PESQUISA EM CIÊNCIAS HUMANAS - SEPECH \\ Humanidades, Estado e desafios didático-científicos \\ Londrina, 27 a 29 de julho de 2016}

acabam sendo tão impactantes a ponto de limitar o olhar de quem consome, ou seja, não existem critérios, não há um olhar crítico para com o que consomem, já que a ilusão de obter o material acaba ultrapassando a questão de precisar para consumir e o que passa a vigorar é o precisar para suprir uma necessidade emocional apenas para suprir o seu próprio ego. Esta falta de escolha própria e, até falta de criticidade frente ao consumo resulta no processo de semiformação, em que este absorve falsas verdades frente ao consumo e as naturaliza. Zuim (2011) afirma:

A conquista do espírito pela lógica universalizada da mercadoria cobra seus dividendos também na esfera da produção de bens simbólicos, de tal modo que o indivíduo semiformado não se sente estimulado a refletir criticamente sobre o que aprende, pois dificilmente consegue aprender algum conhecimento por um tempo que o capacite a elaborá-lo a ponto de poder ressignificar sua própria vida.

Ou seja, o indivíduo não têm pensamentos próprios, sua capacidade de reflexão, questionamento acaba sendo induzido ao processo de repetição e reprodução do meio capitalista e consumidor, sem compreender efetivamente o que está por trás das entrelinhas sociais.

O objetivo central da Indústria Cultural é produzir cultura de massas, que se utiliza de meios de comunicação como rádio, televisão e internet, para disseminar a seus artefatos culturais, criando padrões e modelos a serem seguidos, influenciando a massa consumidora, onde se ter é uma necessidade para ser algo. Todas as classes sociais são atingidas pelo discurso sedutor da mídia, que nos leva a acreditar que o produto ou o ideal de beleza e até mesmo de vida imposto por ela, são indispensáveis para a nossa vida.

Adorno diz que ocorre a padronização dos consumidores

[...] Para todos, alguma coisa é prevista a fim de que nenhum possa escapar; as diferenças vêm cunhadas e difundidas artificialmente. $\mathrm{O}$ fato de oferecer ao público uma hierarquia de qualidades em série serve somente à quantificação mais completa, Cada um deve-se portar, por assim dizer, espontaneamente, segundo o seu nível, determinado $a$ priori por índices estatísticos, e dirigir-se à categoria de produtos de massa que foi preparada para o seu tipo (ADORNO, 2002, p.271)

Tudo é transformado em produto, arte, investimento, entretenimento, acessórios, cinema, estética, música, para todos os gostos e costumes tudo a fim de conquistar o consumidor e obter lucros. A mídia e propaganda assumem papel prioritário no mercado, para alcançar os ideais e os modismos, criando um mundo e um protótipo de individuo que devem ser seguidos e idealizados, fazendo do homem não apenas um simples consumidor nesse mundo das mercadorias, mas também um estimulador do consumo, onde ele será o produto final resultado de todo o seu consumo.

Ao consumir as pessoas satisfazem suas necessidades que foram inseridas culturalmente, o consumo configura a sociedade limitando a forma de pensar, e o mesmo ocorre quando a Indústria Cultural tem como alvo o consumo infantil. As crianças se tornam consumidoras em potencial, sendo estimuladas pela família e a indústria, de todas as formas possíveis, seja no brinquedo, no super - herói do desenho animado que faz a criança se inspirar no nele, seguindo suas ideologias e ações, seja na 


\section{SEMINÁRIO DE PESQUISA EM CIÊNCIAS HUMANAS - SEPECH \\ Humanidades, Estado e desafios didático-científicos \\ Londrina, 27 a 29 de julho de 2016}

indústria alimentícia onde certos alimentos são destinados as crianças, onde marcas surgem e rotulam que o conceito de felicidade está ligado a ela. A criança se torna refém, e por não ter desenvolvido seu senso crítico é manipulada sem nem ao menos saber o que está acontecendo ao certo.

Uma das grandes armas dessa Indústria Cultural para atingir seu público alvo tem sido através da publicidade e propaganda que é destinada a determinado público, influenciando a forma de pensar e compreender a sociedade, fazendo com que o indivíduo perca a capacidade de pensar por si próprio. Tendo como um dos maiores aliados do capitalismo, encontramos a televisão, onde de acordo com o programa escolhido pelo "cliente" é determinado o público que essa propaganda deve atingir como ocorre principalmente na TV aberta em meio aos programas têm os comercias que induzem as pessoas a quererem consumir ainda mais, cirando padrões, onde só se pode ser feliz se "ter".

Nem mesmo as crianças escapam dessa cultura de massas e, acabam que se tornando reféns desde muito cedo, como em assistir um simples desenho, o que é algo comum na vida de toda criança, mas que se estudado mais a fundo tem uma intencionalidade, onde na maioria dos desenhos são implantados os ideais a serem seguidos, sem nem ao menos permitir a criança pensar ou questionar porque têm que ser daquela forma e não de outra.

Em alguns países a propaganda destinada ao público infantil é proibida, ao contrário do que acontece no Brasil, que basta assistir algum programa destinado ao público infantil para ver os exageros cometidos pela cultura de massas, que ilustram diversas situações onde as crianças só podem ser felizes se tiver o que está sendo imposto, e caso não tenha será excluída pelo meio em que está inserida. O grande foco para atingir público infantil são os brinquedos, que também sofreram diversas mudanças e tornaram-se mais um produto a ser comercializado. As crianças aparecem como consumidoras em potencial e futuros adultos adaptados a ordem estabelecida, sem refletir sobre as condições de produção e poder da sociedade capitalista.

Se analisarmos criticamente e der a devida atenção muitos brinquedos criados ao longo da história e que vêm percorrendo décadas são estereótipos de beleza, de como se portar e que ditam padrões de como a coisa realmente deve ser, e os mesmos acompanham o desenvolvimento da sociedade percorrendo os anos acompanhando a cultura e a crescente desenvolvimento da cultura de massas, como é o que ocorre com a boneca Barbie, a queridinha das meninas no universo infantil e de muitos adultos também, é a boneca mais vendida no mundo, como Altmann (2013) nos diz que "o surgimento do que se tornaria a boneca mais vendida do mundo está envolto por um intenso investimento tecnológico, político e publicitário no sentido de viabilizar sua confecção, distribuição e hegemonia em um mercado mundial globalizado".

Em se tratando da Boneca Barbie, vemos que sua história tem início na Alemanha em 1952, com o estouro em vendas da Boneca Lille que não era destinada ao público infantil e sim ao público adulto masculino, pois ao contrário das bonecas da época a boneca Lille apresentava um corpo exuberante, usava roupas curtas, salto alto e era dona de uma beleza estonteante o que incitava o público masculino. A boneca já está no mercado as mais de meio século e o que sempre se vê nela? Uma boneca sempre muito bem vestida, que está muitas vezes à frente de seu tempo, com pele e o corpo impecável, e não importa o tempo, ela sempre está perfeita. 


\section{SEMINÁRIO DE PESQUISA EM CIÊNCIAS HUMANAS - SEPECH \\ Humanidades, Estado e desafios didático-científicos \\ Londrina, 27 a 29 de julho de 2016}

As bonecas Lilli tinham uma aparência alongada e eram vestidas com lindos trajes. Um deles era uma roupa de esqui; outro era um traje típico de uma região da Europa. Ruth e Bárbara nunca haviam visto bonecas como aquelas, exibidas no interior da loja, e Ruth sugeriu que comprassem uma para enfeitar o quarto de Barbara, já que ela havia passado da idade de brincar com bonecas. Barbara ficou encantada, mas, diante das bonecas com trajes tão diferentes, achou difícil escolher uma só. Ruth tentou comprar as roupas separadamente, mas foi informada de que elas não eram vendidas desta maneira. Se um cliente queria um traje diferente, tinha que comprar a boneca junto. (GERBER, 2009, p.19).

Ruth Handler viu pela a primeira vez a boneca Lille e ficou incitada com a diferença da boneca, já que ela representava uma mulher mais velha, então decidiu comprar duas bonecas para sua filha Bárbara. Ruth Handler e seu marido foram os fundadores da empresa Mattel, que atualmente é uma das maiores empresas de brinquedos do mundo, lançado sonhos e padrões no universo infantil, e que viram na boneca Lille uma grande oportunidade para se estabelecer no mercado infantil, então a empresa Mattel compra os direitos autorais da boneca Lille e começam a desenvolver em seu laboratório uma nova boneca, baseada em Lille (ALTMANN, 2013).

A versão da boneca Lille criada pela Mattel foi lançada em 1959 em uma feira de brinquedos em Nova Yorque, a nova versão da boneca possuía um ar mais jovial, mais maquiagem e um sorriso discreto, os fundadores da Mattel fizeram uma homenagem a sua filha Bárbara e chamaram a boneca de Barbie (ALTMANN, 2013).

Ela era uma modelo adolescente. Garotas deixavam de embalar bebês para exibir o mais recente da alta costura à la Matel. A Barbie era sexy apesar de a maioria das proprietárias sequer estarem preocupadas com a sua sexualidade - elas apenas amavam as suas Barbies (STEIBERG, 2004, p.325).

Com o fim da Segunda Guerra Mundial e o crescente estouro do comunismo nos Estados Unidos, as propagandas passam a ser destinadas pela primeira vez ao público infantil, que com a chegada da televisão e o lançamento do Mikey Mouse Show, as crianças passam a ser um novo público para o mercado consumista, o que proporciona o estouro e sucesso da boneca Barbie.

Com mais de meio século de vida, estima-se que desde a sua criação, mais de um bilhão de bonecas Barbies foram vendias em mais de 150 países (LORD, 2004). Que acompanha o status a boneca mais vendida do mundo, no qual seu sucesso está sempre vinculado a um estereótipo de beleza, juventude e consumo.

Ruth Handler e a Mattel não pararam apenas na criação da Barbie, mas ao longo do seu mais de meio século de vida, deram a ela uma "vida". Ao decorrer dos anos a Barbie foi ficando ainda mais linda, acompanhando os padrões de moda, sempre com roupas e acessórios luxuosos, em 1961 Barbie ganha seu namorado Ken, que é uma homenagem ao outro filho de Ruth. Na década de 80 surgem as primeiras Barbies negras, o que faz com que ao longo dos anos a boneca ganhe amigos, casa, carros.

Algumas marterialiedades se sobrepõe a outras, produzindo certas 'normalidades', desse modo é 'natural', no caso do uo de bonecos e bonecas, que os mesmos ao fazerem parte da sala de aula de crianças 


\section{SEMINÁRIO DE PESQUISA EM CIÊNCIAS HUMANAS - SEPECH \\ Humanidades, Estado e desafios didático-científicos \\ Londrina, 27 a 29 de julho de 2016}

pequenas seja da raça branca, e olhos azuis com longos cabelos loiros. Assim tudo que escapa ou se apresenta de maneira diferente dentro desse modelo de 'normalidade', dessa 'verdade' acerca da raça branca, é o 'diferente' o 'outro'. Este é o brinquedo consumido em série para crianças no que tange a 'diferenças' sejam elas raciais de gênero, geração ou etnia. (DORNELLES, 2003, p.4)

A boneca Barbie é um dos brinquedos que mais refletem o comportamento ela é inteligente, rica, está sempre na moda, tem um namorado perfeito, amigos que a adoram, está sempre no centro das atenções, já teve sua versão nas mais variadas profissões, personalidades famosas, Altman nos diz que

Se há algo marcante na história da Barbie é o investimento em torno da boneca. Diferentes estratégias publicitárias transformaram-na em uma personalidade. Barbie não é apenas uma boneca, mas uma marca. Não se trata mais apenas de vender uma boneca, mas de vendê-la com e por meio de inúmeros outros produtos: filmes, roupas e acessórios, carros, móveis, animais de estimação, jogos eletrônicos, sites da internet, decorações de festas infantis, roupas infantis, bolas, ovos de Páscoa e tantos outros produtos quanto se possa imaginar. (ALTMANN, 2013)

Lança o eslingam de seja o que você quiser ser, com um mundo cor de rosa, onde tudo é possível, vendendo sonhos, mostrando através dos personagens criados ao longo dos anos o que as meninas precisam ter ser e fazer para se tornar uma mulher. Trazendo a ideia da imagem, copo e vida perfeita, tornando as crianças consumidoras em potencial. Gerber (2009 p.158) afirma que: "é um produto muito educativo: as crianças aprendem combinações de cores, desenhos de moda, cuidados pessoais, penteados, boas maneiras, e relacionamentos interpessoais - elas interagem por meio de situações sociais".

Mas até que ponto essa relação da criança com um "produto educativo" é importante? O quanto essa relação pode influenciar em sua forma de pensar e agir? Estudos já demonstraram que brincar é essencial para a sobrevivência do ser humano, tanto quanto a nutrição. O brincar é fundamental para o desenvolvimento físico, social, intelectual e afetivo da criança, pois enquanto ela brinca, assimila o mundo ao seu redor, sem compromisso com a realidade, passa a atribuir aos objetos funções próprias, não dependendo da natureza dos mesmos.

Entretanto o mundo criado pela boneca Barbie leva a criança a ir além, sendo o que ela quiser no mundo cor de rosa, impedindo ela de usar sua criatividade e produtividade na hora de brincar o que é fundamental para o seu crescimento. As meninas são fisgadas pelo mundo imaginário cor de rosa, onde tudo é possível, seu mundo incita certas formas de pensar, agir, e se relacionar com o mundo, esse mundo cor de rosa é uma marca, como está no site comemorativo "Viva o Rosa" comemorativo de 50 anos da boneca, onde se encontra um texto direcionado aos pais que diz:

Rosa é a maneira alegre e espontânea de viver, em que cada menina celebra seus sonhos e com ela a possibilidade de ser o que quiser! [...] Viva o rosa reforça a ideia de que cada menina pode transferir para a vida real elementos delicados e femininos que fazem parte do mundo da 


\section{SEMINÁRIO DE PESQUISA EM CIÊNCIAS HUMANAS - SEPECH \\ Humanidades, Estado e desafios didático-científicos \\ Londrina, 27 a 29 de julho de 2016}

boneca. Por isso, convidamos você a participar também deste universo onde o rosa é sinônimo de alegria! (MATTEL, 2009)

A Barbie ensina que a felicidade está na aquisição de bens materiais, no qual sua pedagogia inspira diversas lições de com adquirir bens que deem status, riqueza, que acompanham tendências de moda e um estilo divertido. Fazendo com esses conceitos o indivíduo que entra no mundo cor de rosa se sentir especial, dando ao mesmo um conceito de vida social e de felicidade.

A boneca Barbie se faz imersa a uma pedagogia cultural que tem a intenção de ensinar a supremacia de um copo e comportamento e produzir as subjetividades infantis. A pedagogia analisada na boneca mostra que a pressão da publicidade ao qual está impressa nela é difundida através de diferentes artefatos que incorporam valores e modelos que são inseridos na sociedade atual. A boneca Barbie personifica a fantasia de um mundo glamoroso e um ideal de beleza feminino, magro, branco e loiro.

Diante disso, torna-se desafio pensar que, independentemente das influências da Indústria Cultural e do Consumo, é preciso fomentar os valores humanos (ser) que estão cada dia mais se sendo que essa lógica do consumo não deve ser o objetivo maior na conduta humana, principalmente, na formação do pensamento infantil.

\section{REFERÊNCIAS}

ADORNO, T. L. HORKHEIMER, M. Dialética do Esclarecimento: fragmentos filosóficos. Tradução: Guido A. de Almeida. Rio de Janeiro: Jorge Zahar, 1985.

ALTMANN, Helena. Bárbie e sua história: gênero, infância e consumo. Dísponivel em: $\quad$ http://www.scielo.br/scielo.php?pid=S010373072013000100017\&script $=$ sci_arttext. Acesso em: 12/06/2015

DORNELLES, L. V. Infâncias que nos escapam da criança: da criança na rua a criança cyber. Petrópolis, Vozes, 2008.

GERBER, Robin. Bárbie e Ruth. $1^{\circ}$ Ed. Rio de Janeiro: Ediouro, 2009. P. 19-158.

HORKHEIMER, Max \& ADORNO, Theodor. A indústria cultural: o iluminismo como

LORD, M. G. Forever Barbie - The unauthorized biography of a real doll. New York: Walker \& Company, 2004.

MATTEL. Viva o Rosa - Celebre o aniversário da Barbie. 2009. Disponível em:http://www.barbievivaorosa.com.br/ . Acesso: 15/06/2015.

STEIMBERG, S. R. [et al]. Boy Culture: an ancyclopedia. California: Greenwood Publishing Group, 2010.

ZUIM, Antônio Alvoro Soares. O Plano Nacional de Educação e as Tecnologias de Informação e Comunicação. 2011. Acesso: 15/06/2015. 